\title{
Impacts of the apoptosis inhibitor of macrophage (AIM) on obesity-associated inflammatory diseases
}

\author{
Satoko Arai • Toru Miyazaki
}

Received: 20 October 2013 / Accepted: 23 October 2013 / Published online: 27 November 2013

(C) The Author(s) 2013. This article is published with open access at Springerlink.com

\begin{abstract}
Obesity is associated with various metabolic and cardiovascular diseases caused by chronic, low-grade inflammation that is initially observed in obese adipose tissue. In addition, many etiological studies in humans have shown a strong correlation between obesity and inflammatory autoimmune diseases. In this review, we focus on the involvement of apoptosis inhibitor of macrophage (AIM), a macrophagederived blood protein, in both types of immune response. Through differential mechanisms, AIM thereby plays key roles in the pathogenesis of atherosclerosis, metabolic diseases, and obesity-associated autoimmune diseases. Thus, the regulation of blood AIM levels or AIM function has the potential to serve as a next-generation therapy against these inflammatory diseases brought about by modern lifestyle.
\end{abstract}

Keywords AIM (apoptosis inhibitor of macrophage) · Chronic inflammation $\cdot$ Lipolysis $\cdot \operatorname{IgM} \cdot$ Autoantibody

\section{Obesity-associated inflammatory diseases in modern society}

The prevalence of obesity is rapidly increasing due to drastic changes in lifestyle, particularly eating habits. Obesity is

This article is a contribution to the special issue on Metabolic Syndrome Guest Editor: T. Miyazaki

S. Arai $(\bowtie) \cdot$ T. Miyazaki

Laboratory of Molecular Biomedicine for Pathogenesis,

Center for Disease Biology and Integrative Medicine,

Faculty of Medicine, The University of Tokyo, 7-3-1 Hongo,

Bunkyo-ku, Tokyo 113-0033, Japan

e-mail: sarai@m.u-tokyo.ac.jp

T. Miyazaki

e-mail: tm@m.u-tokyo.ac.jp

T. Miyazaki

CREST, Japan Science and Technology Agency, 7-3-1 Hongo,

Bunkyo-ku, Tokyo 113-0033, Japan closely associated with insulin resistance, which triggers and/or accelerates multiple metabolic disorders including type 2 diabetes, cardiovascular diseases, and fatty liver dysfunction. It is widely known that insulin resistance is caused by chronic, low-grade inflammation in obese adipose tissue [1-5]. This subclinical state of inflammation is dependent mainly on the innate immune system through the activation of Toll-like receptors (TLR) expressed on adipocytes by fatty acids, a process which leads to the production of inflammatory adipokines and the recruitment of classically activated inflammatory macrophages (M1 macrophages) into obese adipose tissue [6-8]. Lean adipose tissue contains a resident population of alternatively activated macrophages (M2 macrophages), which can suppress the inflammatory response induced by both adipocytes and macrophages partly via the secretion of interleukin-10. Hence, obesity induces a switch in the macrophage activation state in adipose tissue towards M1-polarization, which subsequently leads to inflammation [9-12].

In addition to metabolic and cardiovascular diseases, many etiological and clinical studies in humans have shown a strong correlation between obesity and autoimmune diseases. These conditions are largely accompanied by increased levels of autoantibodies such as diabetes-associated antibodies against pancreatic $\beta$-cell antigens (e.g. insulin, glutamic acid decarboxylase (GAD), and protein tyrosine phosphatase-like protein, IA2), chronic thyroiditis-associated anti-thyroid peroxidase or anti-thyroglobulin antibody, and infertility-associated anti-sperm antibody [13-17]. In addition, pathogenic immunoglobulin (Ig) $\mathrm{G}$ antibodies, including a unique profile of autoantibodies, have been found in obese humans and mice [18].

The association between obesity and inflammatory diseases can be attributed to two distinct immunological responses: chronic inflammation through stimulating innate immunity leading to insulin resistance and activation of a humoral immune response that triggers autoantibody production. 
In this review, we discuss the pathogenesis of obesityassociated inflammatory diseases from the immunological perspective by focusing on the apoptosis inhibitor of macrophage (AIM, also known as $\mathrm{Sp} \alpha$ and CD5L) [19]. We initially identified AIM as an apoptosis inhibitor that supports the survival of macrophages against various apoptosis-inducing stimuli [19]. However, our recent studies revealed that AIM is involved in the progression of both types of obesity-associated inflammatory response though differential mechanisms.

\section{Apoptosis inhibitor of macrophage}

AIM protein is a secreted protein of the scavenger receptor cysteine-rich superfamily [20]. Although the protein sequences of human and mouse AIM are well conserved, large differences exist in the glycosylation states; mouse AIM is heavily glycosylated with $N$-glycans, whereas human AIM is not $N$-glycosylated. We previously demonstrated that such a $\mathrm{N}$-glycosylation state influences the activity and secretion efficiency of AIM protein [21].

AIM is produced solely by tissue macrophages under transcriptional regulation by nuclear receptor liver $\mathrm{X}$ receptor/ retinoid X receptor (LXR/RXR) heterodimers [19, 22-24] and is therefore expressed in lipid-laden macrophages in atherosclerotic lesions. We demonstrated that AIM induction is associated with atherosclerogenesis by supporting the survival of macrophages within lesions [24]. Indeed, atherosclerotic plaques were markedly reduced in size in mice doubly deficient for AIM and the low-density lipoprotein (LDL) receptor $\left(A I M^{-/} L D L^{-/}\right)$compared with $A I M^{+/ 4} L D L^{-/-}$mice fed a high-cholesterol diet [24, 25].

As a secreted molecule, AIM is detected at varying levels in human and mouse blood [26-32]. Interestingly, serum AIM increased with the progression of obesity in mice fed a highfat diet (HFD) [31]. Other studies have suggested that AIM is multifunctional and effective in cell types other than macrophages, including B and natural killer T lymphocytes [33-35]. In addition, Lozano's group reported that AIM attaches to certain bacteria and induces their coagulation [36]. This "sticky" characteristic is a hallmark of scavenger receptor cysteine-rich superfamily proteins [20, 37-39].

\section{AIM induces lipolysis in adipocytes suppressing an increase in fat mass}

In addition to its apoptosis inhibitory effect, we found that AIM induces lipolysis in adipose tissue. When differentiated 3T3-L1 adipocytes in culture were challenged with AIM, the size and the number of lipid droplets of triacylglycerol within the adipocytes markedly decreased [31]. Through this AIMinduced lipolytic response, a certain amount of glycerol and free fatty acids (FFA), the constituents of triacylglycerol, were effluxed from the cells $[40,41]$. In support of these in vitro observations, production of both visceral and subcutaneous fat tissue was accelerated in $A I M^{-/}$mice fed a HFD (60\% fat) compared with $A I M^{+/+}$mice fed the same diet. In addition, basal levels of serum FFA and glycerol were lower in obese $A I M^{-/}$mice than in obese $A I M^{+/+}$mice [31]. These differences in $\mathrm{AIM}^{-/}$and $\mathrm{AIM}^{+/+}$mice were corrected by the intraperitoneal administration of recombinant AIM [31]. Interestingly, both obese $\mathrm{AIM}^{-/-}$mice and $\mathrm{AIM}^{+/+}$mice showed comparable metabolic parameters (e.g., body temperature, oxygen consumption, and food intake) and locomotor activity [31]. Thus, AIM influences adipose tissue mass, which essentially regulates fat and body weight, through specifically affecting adipocytes.

Interestingly, unlike most ligands in the blood, such as cytokines and growth factors, which bind to specific receptors and mediate signal transduction to affect their target cells, blood AIM is incorporated into adipocytes via endocytosis mediated by the CD36 scavenger receptor and functions directly in the cytosol of the target cells [31]. Such direct functioning in the absence of signaling is unusual in secreted molecules, with only a limited number of reported examples, including fibroblast growth factors-1 and -2 [42, 43] and epidermal growth factor [44], in which the cytosolic delivery of exogenous proteins was shown to mediate the biological effects in mammalian cells, and also in some plant and bacterial toxins $[45,46]$. In addition, some exogenous antigens in dendritic cells can access the cytosol via machinery similar to that for intracellular transport where they are presented by major histocompatibility complex class I molecules [47, 48]. The mechanism responsible for AIM translocation from the endosomal compartment into the cytosol remains unknown.

\section{Two independent modes of lipolysis induction}

Lipolysis usually occurs during periods of energy deprivation. Under fasting conditions, increased amounts of catecholamine are released from the hypothalamus and bind to the $\beta$ adrenergic receptor, thereby mediating the cyclic adenosine monophosphate (cAMP)-dependent signaling cascade. This response phosphorylates protein kinase A (PKA), which activates hormone-sensitive lipase (HSL) and increases the levels of the adipose triglyceride lipase (ATGL) mRNA [49-55].

In contrast, AIM does not mediate signals. Despite lipolytic consequences, no HSL phosphorylation was observed in AIM-treated adipocytes in vitro $[31,56]$. In vivo phosphorylation of HSL or its upstream PKA in epididymal adipose tissue was not enhanced in obese wild-type mice compared with lean mice, although lipolysis was apparently enhanced, given the elevated serum levels of FFA and glycerol [56]. Similarly, $A I M^{-/}$mice fed a HFD showed no increase in 
HSL phosphorylation. In addition, forced induction of lipolysis in obese $A I M^{-/}$mice by intravenous injection of AIM activated neither HSL nor PKA phosphorylation in epididymal adipose tissue [56]. In accordance with these observations, increased HSL and PKA phosphorylation levels were comparably detected in the epididymal adipose tissue of $A I M^{-/-}$and $A I M^{+/ 4}$ mice in response to 24-h fasting [56].

In the cytosol of adipocytes, incorporated AIM associates with fatty acid synthase (FASN), which is highly expressed in adipose tissue and catalyzes the synthesis of saturated fatty acids, such as palmitate, from acetyl-CoA and malonyl-CoA precursors $[31,56]$. This binding of AIM remarkably reduces the enzymatic activity of FASN $[31,56]$. Consistent with this finding, FASN activity was significantly increased in the epididymal fat of $A I M^{/-}$mice compared with $A I M^{+/+}$mice and was subsequently decreased following direct injection of AIM. Since treatment of adipocytes with AIM or the FASN inhibitor C75 has similar lipolytic consequences, the lipolytic effect of AIM on adipocytes is likely due to the suppression of FASN activity $[31,56]$. Thus, two distinct modes of lipolysis occur in different physiological situations: catecholamine-dependent lipolysis under fasting conditions and AIM-induced lipolysis under obese conditions.

\section{AIM targets lipid droplet-coating proteins via regulating PPAR $\gamma$ activity}

Numerous studies have suggested that polyunsaturated fatty acids and related molecules can activate peroxisome proliferator-activated receptor (PPAR) $\gamma$, a master transcription factor for the differentiation of adipocytes, although the identity of the biological ligand(s) for PPAR $\gamma$ has not been elucidated [57-60]. Metabolomics analysis revealed that the proportion of palmitic acid (C16:0), the primary product synthesized by FASN, was significantly reduced in adipocytes treated with AIM. Similarly, the proportions of multiple saturated fatty acids harboring longer chains such as stearic acid (C18:0) and related unsaturated fatty acids are also reduced in response to AIM [56].

Interestingly, the transcription of different lipid coating genes, including FSP27 and Perilipin, whose mRNA levels decrease in response to AIM in adipocytes [31], is directly regulated by PPAR $\gamma[61,62]$. It is plausible then that suppression of FASN activity by AIM reduces the production of PPAR $\gamma$ biological ligand(s), thereby decreasing the transcriptional activity of PPAR $\gamma$ and resulting in downregulation of the droplet-coating gene expression that leads to lipolysis (Fig. 1). We corroborated this idea as follows [56]. First, we assessed whether the presence of rosiglitazone, a selective PPAR $\gamma$ agonist, or T0070907, a selective PPAR antagonist, influenced the lipolytic effect of AIM in 3T3-L1 adipocytes. Several parameters with remarkable involvement in AIMinduced lipolysis (i.e. increased glycerol efflux, downregulation of FSP27 and Perilipin mRNA levels, and increased inflammatory gene expression) were inhibited by the presence of rosiglitazone in a dose-dependent fashion. In contrast, a synergistic effect of these lipolytic consequences was detected following combined administration of recombinant AIM and
Fig. 1 Two modes of lipolysis distinguished by AIM. Catecholamine mediates signals thereby activates and/or augments lipases which directly degrade $\mathrm{TG}$, leading to lipolysis. In contrast, AIM decreases lipid droplet-coating proteins via reducing FASN activity, without influencing lipases

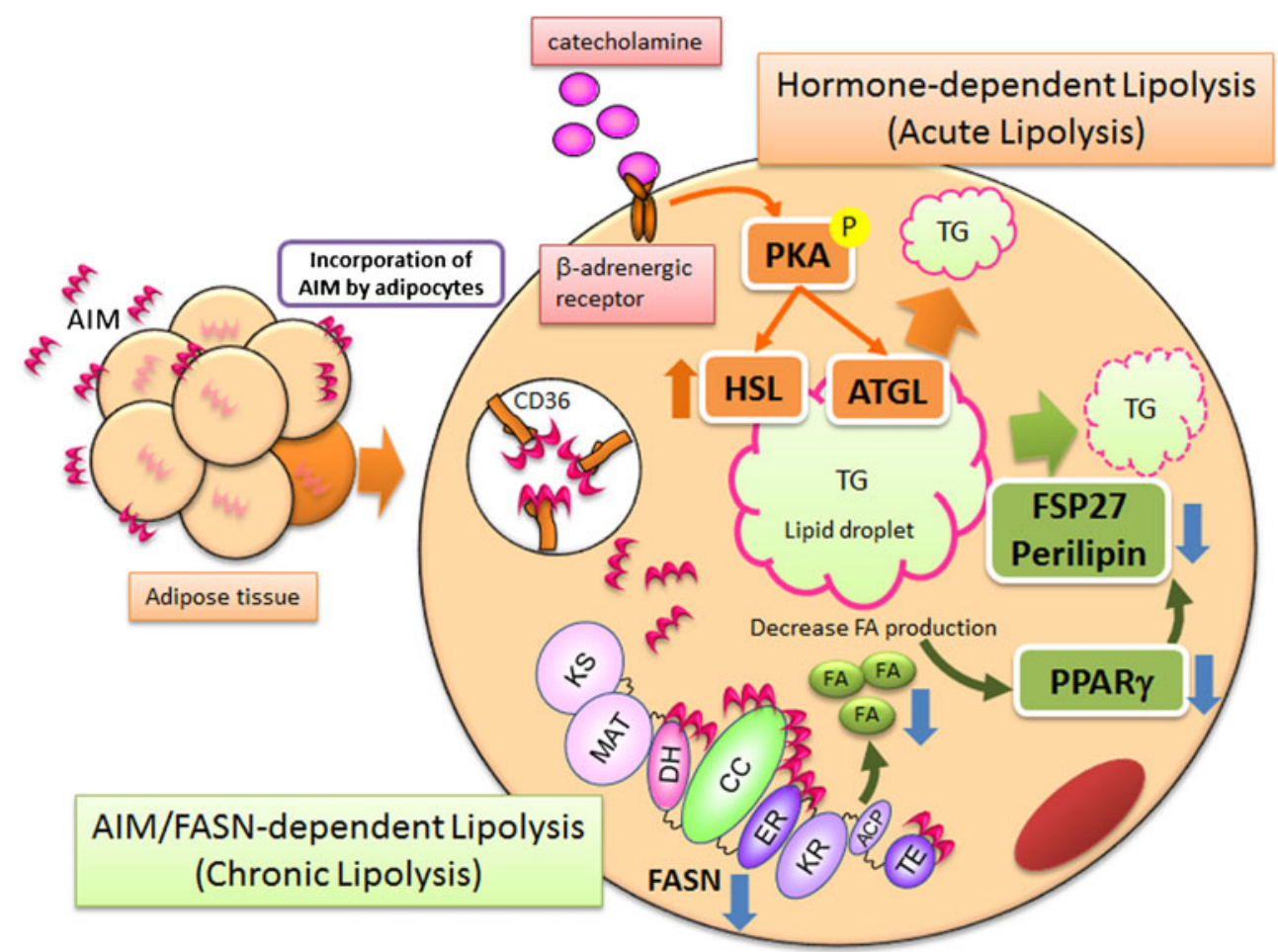


T0070907. Second, we assessed the effect of AIM on the transcriptional activity of PPAR $\gamma$ more directly by creating 3T3-L1 adipocytes stably transfected with a luciferase reporter gene conjugated with a PPAR-binding element (PPRE) at the 5' end [57]. Challenge with AIM significantly decreased the luciferase activity in a dose-dependent fashion, as with T0070907. In addition, the luciferase activity induced by rosiglitazone was significantly suppressed by AIM.

\section{AIM-induced lipolysis mediates migration of macrophages into adipose tissue}

The suppressed lipolytic state of adipose tissue in $A I M^{-/}$ mice [31] results in more advanced adipocyte hypertrophy than in $\mathrm{AIM}^{+/+}$mice, and the overall mass of visceral fat and body weight is markedly greater [31]. It is interesting to note, however, that the obesity-associated infiltration of inflammatory macrophages (M1 macrophages) into adipose tissue was dramatically suppressed in $A^{\prime \prime} M^{-/}$mice compared with $A I M^{+/+}$mice after being fed a 12-week HFD [63]. In addition, the administration of AIM to obese $\mathrm{AIM}^{-/}$mice resulted in an accumulation of M1 macrophages in adipose tissue [63]. Thus, the presence of AIM is indispensable for obesity-associated recruitment of adipose tissue macrophages. However, AIM exhibits no chemoattractive activity in a macrophage migration assay. By contrast, conditioned medium from adipocytes that had been challenged with AIM efficiently attracted macrophage cells [63]. Furthermore, conditioned medium from adipocytes treated with AIM in the presence of a CD36-neutralizing antibody to inhibit AIM-dependent lipolysis [31] did not efficiently attract macrophages, suggesting that AIM-induced lipolysis in adipocytes is responsible for macrophage recruitment.

Previous studies have demonstrated that saturated fatty acids activate TLR4 and that this response is tightly associated with obesity-induced inflammation [64-68]. Thus, it is plausible that an increase in blood AIM induces vigorous lipolysis in obese adipose tissue and that saturated fatty acids effluxed from adipocytes as a result of lipolysis might activate chemokine production in adipocytes via the stimulation of TLR 4 in a paracrine/autocrine fashion [69-71]. Indeed, palmitic acid and stearic acid, the major fatty acids comprising triglyceride droplets [72] and well-known stimulators of TLR4 [18, 68, $73,74]$, were identified as the components released by adipocytes in response to AIM-induced lipolysis. Consistent with this finding, conditioned medium from adipocytes treated with AIM efficiently activated the TLR signaling cascade in adipocytes, inducing the degradation of I-kappa-B-alpha (IKB $\alpha$ ) and the production of chemokines such as monocyte chemotactic protein (MCP)-1, chemokine (C-C motif) ligand 5/RANTES, MCP-2, and MCP-3. Similar effects of TLR activation and chemokine production were observed when
3T3-L1 adipocytes were treated with palmitic acid and stearic acid [63]. Similarly, when AIM was injected into wild-type or $T L R 4^{-/}$mice, induction of chemokine mRNA was significantly less efficient compared with wild-type mice, although lipolysis was induced in both wild-type and $T L R 4^{-/}$mice, as shown by the increased serum FFA and glycerol levels [63].

Taken together, lipolysis induced by increased blood AIM under obese conditions releases large amounts of saturated fatty acids from adipocytes. This response stimulates chemokine production in adipocytes via TLR4 activation, resulting in M1 macrophage migration (Fig. 2).

\section{Absence of inflammation and insulin resistance in obese AIM $^{-1}$ mice}

The progression of obesity-associated inflammation is prevented both locally and systemically in obese $\mathrm{AIM}^{-/}$mice due to the abolished infiltration of inflammatory macrophages. Accordingly, substantial insulin-stimulated phosphorylation of AKT/ protein kinases protein kinase B and glycogen synthase kinase 3-beta [75] was observed in adipose tissue, skeletal muscle (the gastrocnemius), and liver of $A I M^{-1-}$ mice in contrast to the markedly diminished phosphorylation in $\mathrm{AIM}^{+/+}$mice [63]. Thus, insulin sensitivity was maintained in obese $A I M^{-/}$mice. Similarly, whole-body glucose intolerance and insulin resistance observed in obese $A I M^{+/+}$mice were ameliorated in obese $A I M^{-/}$mice, as shown by intraperitoneal glucose and insulin tolerance tests [63]. Thus, the absence of AIM apparently prevents insulin resistance under obese conditions.

\section{AIM and autoimmune-susceptible natural IgM}

Another recent topic regarding AIM is its involvement in obesity-associated autoimmune diseases. As briefly described earlier, it is well known that obesity in humans often increases the serum levels of multiple autoantibodies, definitively causing autoimmune diseases. However, the elements involved in this autoimmune process and the overall contribution of obesity to autoantibody production remain unclear.

Due to the germline $\mathrm{V}$ gene segment, a large proportion of natural IgM is polyreactive to not only foreign antigens but also autoantigens, including nucleic acids, heat shock proteins, carbohydrates, and phospholipids [76-78]. Thus, IgM is believed to be important for the progression of autoimmunity. Moreover, natural IgM has a relatively low antigenbinding affinity that is compensated for by the pentameric nature of secreted IgM. This forms an immune complex (IC) with antigens and the complement component $\mathrm{C} 3$ which is subsequently deposited on splenic follicular dendritic cells (FDC) [79-82]. Antigen presentation by FDC ICs to follicular 


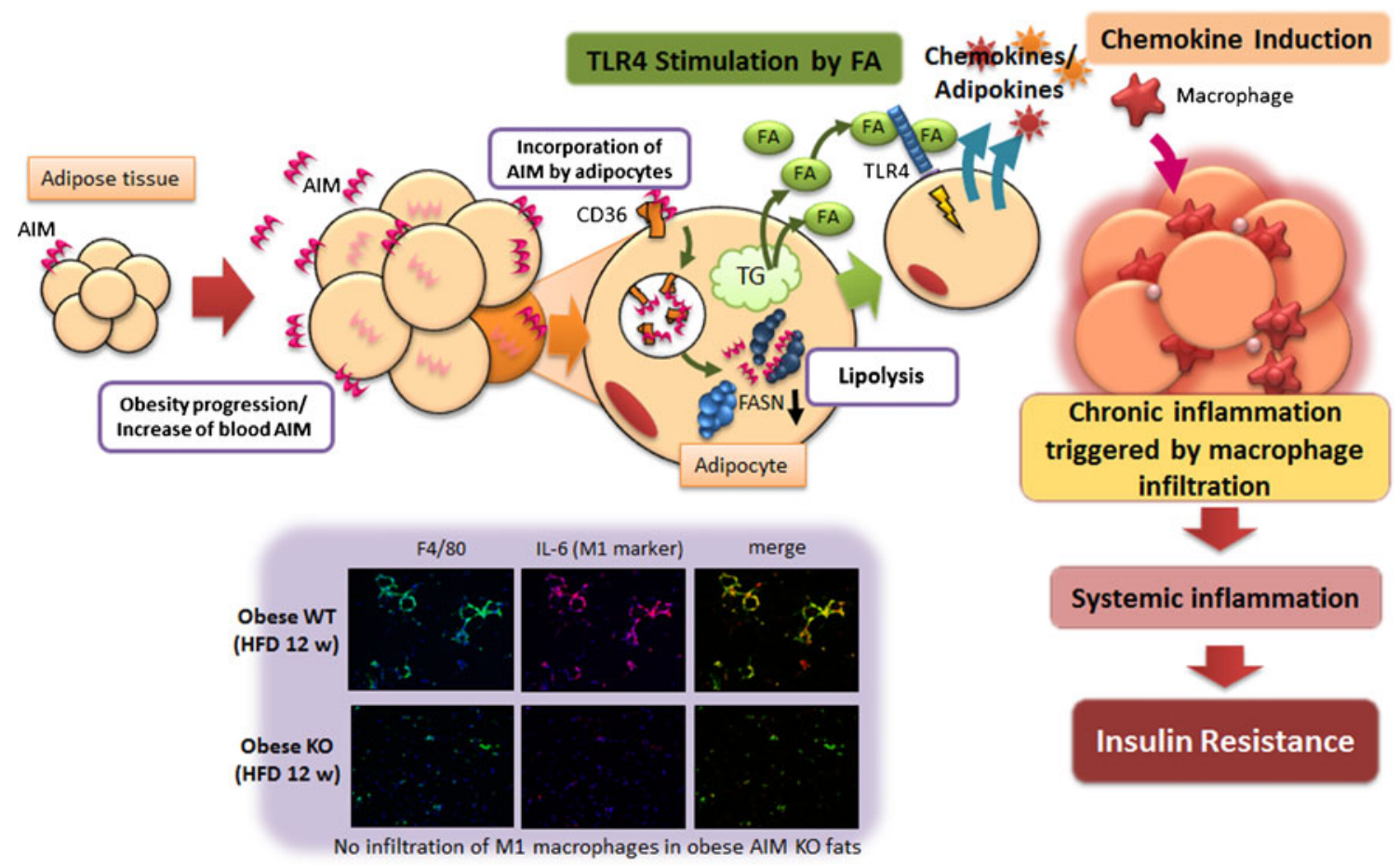

Fig. 2 A scheme of how excess of AIM-dependent lipolysis induces adipose tissue macrophage recruitment. No inflammatory macrophage infiltration in fat tissue in obese $\mathrm{AIM}^{-/}$mice (lower photos)

$\mathrm{B}$ cells is required for the development of long-lived plasma cells that produce high-affinity IgG [83]. Therefore, IgM-IC bound to autoantigens should stimulate the autoantibody response that mediates the progression of autoimmunity.

Interestingly, the potential association between AIM and natural IgM in human blood has been suggested, although its physiological significance is entirely unknown [84]. Indeed, when size-fractionated wild-type mouse serum was assessed for the presence of AIM and IgM, the fractions containing AIM and IgM overlapped precisely at a high molecular weight $(>500 \mathrm{kDa})$, suggesting that most circulating AIM is associated with IgM pentamers [32]. Experiments with different monoclonal IgM clones revealed that AIM likely binds to the Fc region, since AIM binds to IgM regardless of the type of variable region. In contrast, AIM does not bind to $\mathrm{IgG}$ in vivo or in vitro.

\section{Association between AIM and IgM maintains blood AIM levels}

Before discussing autoimmunity, we would like to briefly mention the beneficial association between IgM and AIM. A strong correlation between AIM and natural IgM levels in the blood has been found in both humans and mice. Accordingly, the serum AIM level was far lower in mice lacking blood IgM, such as secreted-type IgM-deficient $(\Delta s \mu)$ mice [85], than in wild-type mice, although the AIM mRNA level in macrophages was comparable in various tissues in all types of mice [32]. Hence, the association between AIM and IgM increases the protein stability of AIM in the blood. In agreement with these findings, intravenous injection of monoclonal mouse IgM rapidly increased serum AIM levels in $\Delta \mathrm{s} \mu$ mice.

The mechanism of how the association between IgM and AIM stabilizes blood AIM levels is as follows: Free AIM is excreted in the urine, but this response is prevented when AIM forms a complex with IgM, resulting in accumulation of AIM in the blood [32]. This complex formation maintains the blood AIM level at a relatively high concentration $(\sim 10 \mu \mathrm{g} / \mathrm{ml})$. Indeed, when AIM was injected into mice doubly deficient for $\mathrm{s} \mu$ and $\operatorname{AIM}\left(\Delta \mathrm{s} \mu A I M^{--}\right)$and into $A I M^{-/}$mice, the decrease in serum AIM levels was more prominent in the $\Delta \mathrm{s} \mu$ $A I M^{-/}$mice. In parallel, AIM excretion in the urine was notably higher in $\Delta \mathrm{s} \mu \mathrm{AIM}^{-/}$. By contrast, AIM did not appear to contribute to the protein stability of $\operatorname{IgM}$ as both $\mathrm{AIM}^{+/+}$and $\mathrm{AIM}^{-/}$mice showed comparable levels of blood $\operatorname{IgM}$.

\section{AIM involvement in IgM-dependent antibody maturation in the spleen}

It is well known that IgM-IC is deposited on splenic FDC through an interaction between the complement component $\mathrm{C} 3$ within the complex and the FDC complement receptor (CD21/CD35), and presents antigens to germinal center (GC) 
B cells [79-83]. Interestingly, IgM-IC remains on the FDC surface for a long time, which increases the probability of coming into contact with highly matched B-cell receptorbearing GC-B cells. Such contact induces differentiation into mature plasma cells.

When spleen specimens from wild-type mice were stained for AIM, IgM, and FDC, accumulations of both AIM and IgM were specifically observed in FDC within splenic GCs [32]. Notably, this co-existence of AIM is required for the retention of IgM-IC with antigens on the FDC surface [32] and has been corroborated by two sets of experiments. First, IgM alone or in association with recombinant AIM (IgM/AIM) was intravenously injected into $\Delta \mathrm{s} \mu A I M^{-/}$mice, and the presence of IgM on the FDC cell surface was tested kinetically. Injection of IgM alone showed no significant deposition on the FDC surface, whereas injected of IgM/AIM revealed profoundly increased FDC IgM levels. The increase was still obvious $48 \mathrm{~h}$ after the injection. Second, the retention of antigens on the FDC surface was tested using the 2,4,6-trinitrophenyl (TNP) antigen, which was shown to be bound to IgM. When TNP conjugated with Ficoll was injected into $\mathrm{AIM}^{+/+}$and $\mathrm{AIM}^{-/}$ mice, the TNP antigen was maintained on the FDC surface more efficiently in $\mathrm{AIM}^{+/+}$mice than in $\mathrm{AIM}^{-/}$mice. Consistent with this finding, the splenic FDC area stained positive for TNP $48 \mathrm{~h}$ after the injection in both mice strains, but there was markedly less staining in $A^{-/ M^{-}}$mice.

\section{AIM interferes with the binding of IgM to the $F(\alpha / \mu$ receptor}

Then, what is the mechanism of how AIM supports the retention of IgM-IC on the FDC surface? We focused on the $\mathrm{Fc} \alpha / \mu \mathrm{R}$, the Fc-receptor for both IgM and IgA [86], because $\mathrm{Fc} \alpha / \mu \mathrm{R}$ expression is detected mainly on the FDCs [86, 87] and the $\mathrm{Fc} \alpha / \mu \mathrm{R}$ induces internalization of IgM, thereby reducing IgM retention on the cell surface [86]. To analyze the influence of AIM on IgM binding to the $\mathrm{Fc} \alpha / \mu \mathrm{R}$, we treated HEK293T cells expressing the Fc $\alpha / \mu \mathrm{R}$ with a monoclonal IgM with or without AIM association. Flow cytometry showed that the association between AIM and IgM markedly decreased the binding of IgM to the Fc $\alpha / \mu$ R. Similarly, Fc $\alpha /$ $\mu \mathrm{R}$-expressing HEK293T cells incubated with serum from $A I M^{+/ 4}$ mice showed reduced surface staining for IgM compared with cells incubated with $A I M^{-1}$ serum. Consistent with the binding results, incorporation of IgM by the cells through the $\mathrm{Fc} \alpha / \mu \mathrm{R}$ was also drastically disturbed by the association of AIM. Thus, AIM interferes with the binding of IgM to the $\mathrm{Fc} \alpha / \mu \mathrm{R}$ and its internalization through antagonizing the receptor. Taken together, it is likely that the presentation of IgM-dependent antigens on the surface of splenic FDC to GC-B cells is deficient in $A I M^{-/}$mice due to rapid internalization of IgM-IC via the $\mathrm{Fc} \alpha / \mu \mathrm{R}$.

\section{B-cell TLR4 mediates the obesity-associated increase in natural IgM levels}

As expected from the correlation between AIM and natural IgM levels in the blood, IgM levels were markedly increased in line with AIM levels [31] in wild-type mice fed a HFD. Evidence suggests that stimulation of cell surface TLR4 activates splenic marginal zone B cells, a major producer of natural IgM [88-90], and subsequently induces high amounts of polyclonal IgM production in an antigen-independent fashion $[91,92]$. Indeed, no significant increase in blood IgM levels was observed in $T L R 4^{-/}$mice fed a HFD for 6 weeks, suggesting that the increase in natural IgM levels in obese mice was brought about by the stimulation of TLR4 expressed on B cells. It is very likely that increased levels of fatty acids, which are effluxed from obese adipocytes and/or directly supplied by a HFD, may activate B-cell TLR4 [64].

\section{Obesity-associated autoantibody production is supported by AIM}

Because of the self-reactive nature of natural IgM, its augmentation might stimulate $\operatorname{IgG}$ autoantibody production in obese mice. This was tested in a proteome microarray containing 70 autoantigens [93-95], using the serum from obese wild-type mice. Compared with lean mice, serum from mice fed a HFD for 12 weeks contained significantly increased levels of $\operatorname{IgG}$ autoantibodies against more than 30 variable autoantigens related to DNA, U1RNP, histone, SSA/SSB, and the cell matrix. In contrast, serum from $A_{I M}^{-1}$ mice fed a HFD for the same period revealed markedly lower levels of IgG antibodies against most of the autoantigens to which the $A I M^{+/+}$serum responded [32]. Consistent with these findings, flow cytometry showed a decreased number of long-lived plasma cells [96], which produce high-affinity IgGs, in the bone marrow of obese $A I M^{-1}$ mice compared with obese $A I M^{+/+}$mice. Thus, the lack of AIM annuls the IgMdependent maturation of high-affinity IgG-producing plasma B cells, tempering obesity-associated IgG autoantibody production (Fig. 3).

\section{Conclusion}

In this article, we have reviewed the key roles of AIM in controlling the progression of multiple obesity-associated inflammatory diseases. The relationship between obesity and blood AIM levels is analogous to that of the accelerator and brake in a car. The more speed (body fat) we gain, the more braking (blood AIM) we need to reduce the speed to keep the car under control. In this regard, AIM is beneficial for impeding the progression of obesity. Under "severely obese" 


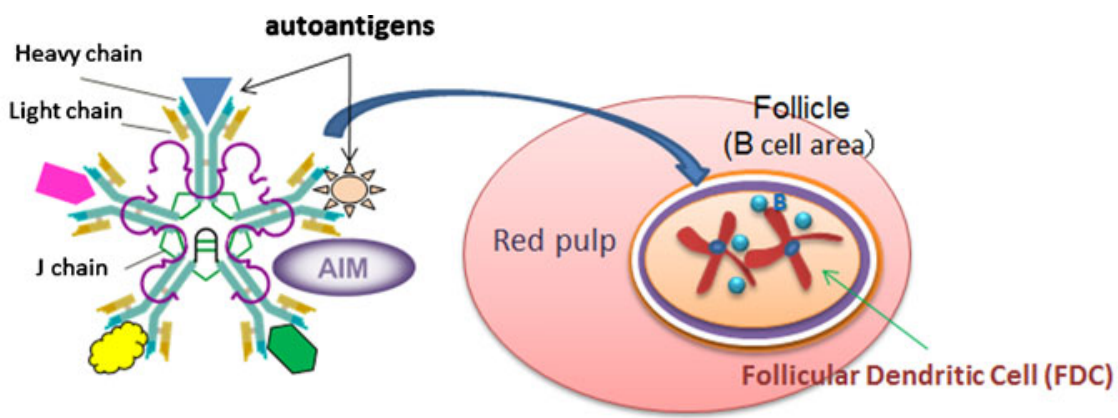

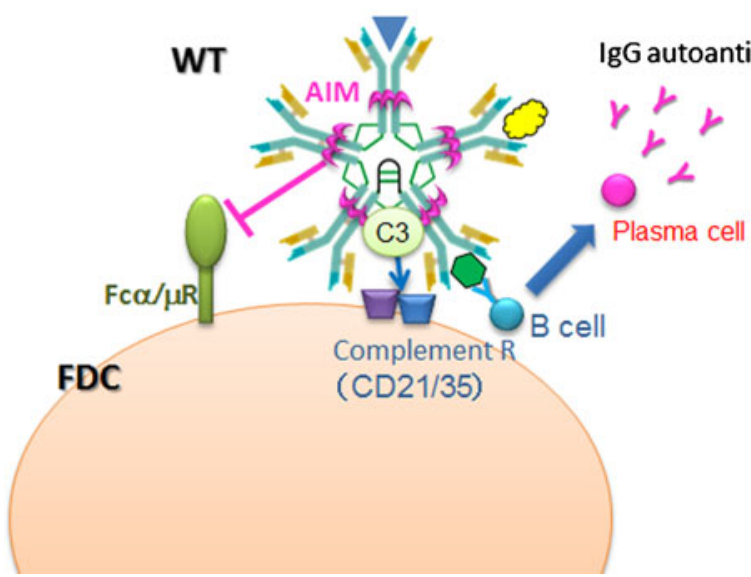

Fig. 3 The role of AIM in obesity-associated autoantibody production. In blood, AIM is associated with IgM pentamer, and thus translocates to splenic GC with IgM/autoantigen complex (upper scheme). There, AIM supports the retention of IgM on the FDC cell surface by interfering with the IgM incorporation into FDC which is mediated by $\mathrm{Fc} \alpha / \mu$ receptor.

conditions, however, body fat and blood AIM behave as if the accelerator and brake are applied simultaneously at very high intensity: such a situation will cause extensive damage to the

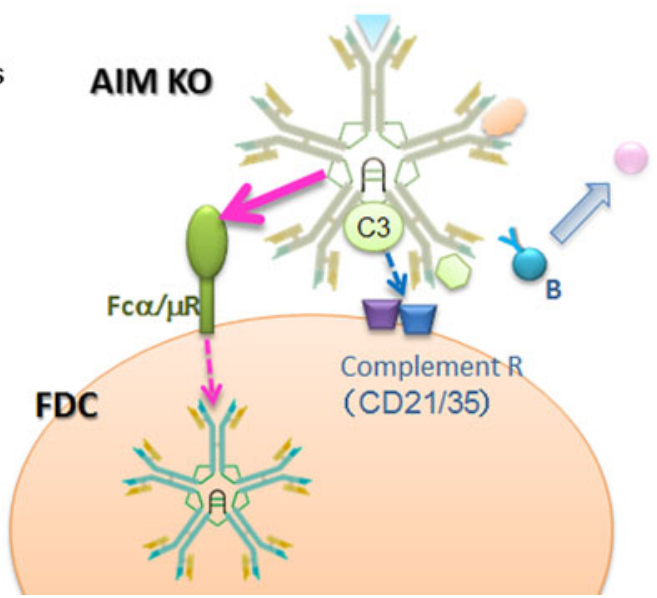

This results in efficient autoantigen presentation to GC-B cells, leading to development of high-affinity autoantibody producing plasma cells (WT). In contrast, in the absence of AIM, the IgM/autoantigen complex is internalized by $\mathrm{Fc} \alpha / \mu$, resulting in less efficient autoantigen presentation, overall leading to suppression of autoimmunity $(K O)$

car. Similarly, severe damage will occur to our body. Excess fatty acids are effluxed from adipocytes due to excessive AIM-induced lipolysis. This process stimulates adipocyte
Fig. 4 To prevent obesityassociated inflammatory diseases

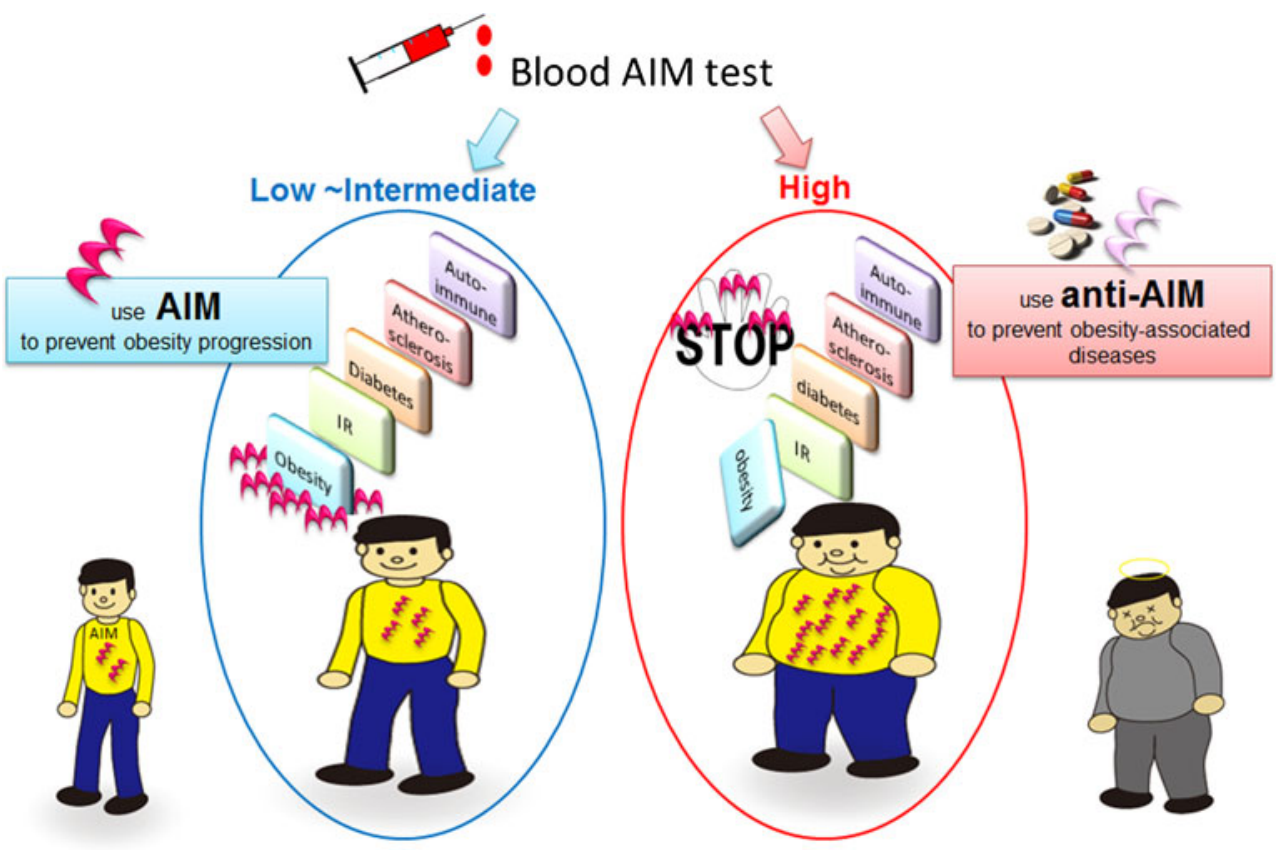


TLR4 levels, which results in the release of chemokines, which in turn recruits inflammatory macrophages into the adipose tissue, leading to insulin resistance. In this regard, AIM is detrimental for metabolic disorders. Thus, during the early phases of metabolic syndrome prior to developing prominent obesity with limited lipid storage in adipocytes, AIM can prevent the progression of obesity via lipolysis, while the reduction of blood AIM levels or inhibition of AIM function will protect very obese individuals from developing metabolic inflammatory diseases such as diabetes, cardiovascular diseases, and autoimmune diseases.

To conclude, the combined application of AIM (i.e., AIM agonists) and anti-AIM (i.e., AIM antagonists) has the potential to serve as a next-generation therapy for preventing harmful obesity-associated inflammatory diseases brought about by modern lifestyles (Fig. 4). We are currently conducting large-scale cohort studies to determine the blood AIM levels in both healthy individuals and patients with various diseases. We anticipate that our results will be useful for establishing the threshold levels of blood AIM, which will subsequently help us decide whether an AIM agonist or AIM antagonist should be used.

Acknowledgments We thank Drs. J. Kurokawa, M. Mori, Y. Iwamura for assistance and discussion. This work was supported by the Global COE Research Program, Grants-in-Aid for Scientific Research (B), and JST, CREST.

Open Access This article is distributed under the terms of the Creative Commons Attribution License which permits any use, distribution, and reproduction in any medium, provided the original author(s) and the source are credited.

\section{References}

1. Hotamisligil GS, Shargill NS, Spiegelman BM (1993) Adipose expression of tumor necrosis factor-alpha: direct role in obesity-linked insulin resistance. Science 259:87-91

2. Wellen KE, Hotamisligil GS (2003) Obesity-induced inflammatory changes in adipose tissue. J Clin Invest 112:1785-1788

3. Arkan MC, Hevener AL, Greten FR, Maeda S, Li ZW, Long JM, Wynshaw-Boris A, Poli G, Olefsky J, Karin M (2005) IKK-beta links inflammation to obesity-induced insulin resistance. Nat Med 11:191198

4. Shoelson SE, Lee J, Goldfine AB (2006) Inflammation and insulin resistance. J Clin Invest 116:1793-1801

5. Neels JG, Olefsky JM (2006) Inflamed fat: what starts the fire? J Clin Invest 116:33-35

6. Weisberg SP, McCann D, Desai M, Rosenbaum M, Leibel RL, Ferrante AW Jr (2003) Obesity is associated with macrophage accumulation in adipose tissue. J Clin Invest 112:1796-1808

7. Xu H, Barnes GT, Yang Q, Tan G, Yang D, Chou CJ, Sole J, Nichols A, Ross JS, Tartaglia LA, Chen H (2003) Chronic inflammation in fat plays a crucial role in the development of obesity-related insulin resistance. J Clin Invest 112:1821-1830

8. Solinas G, Vilcu C, Neels JG, Bandyopadhyay GK, Luo JL, Naugler W, Grivennikov S, Wynshaw-Boris A, Scadeng M, Olefsky JM,
Karin M (2007) JNK1 in hematopoietically derived cells contributes to diet-induced inflammation and insulin resistance without affecting obesity. Cell Metab 6:386-397

9. Gordon S (2003) Alternative activation of macrophages. Nat Rev Immunol 3:23-35

10. Gordon S, Taylor PR (2005) Monocyte and macrophage heterogeneity. Nat Rev Immunol 5:953-964

11. Lumeng CN, Bodzin JL, Saltiel AR (2007) Obesity induces a phenotypic switch in adipose tissue macrophage polarization. J Clin Invest 117:175-184

12. Mantovani A, Sica A, Sozzani S, Allavena P, Vecchi A, Locati M (2004) The chemokine system in diverse forms of macrophage activation and polarization. Trends Immunol 25:677-686

13. Rosenbloom AL (2003) Obesity, insulin resistance, beta-cell autoimmunity, and the changing clinical epidemiology of childhood diabetes. Diabetes Care 26:2954-2956

14. Hersoug LG, Linneberg A (2007) The link between the epidemics of obesity and allergic diseases: does obesity induce decreased immune tolerance? Allergy 62:1205-1213

15. Cambuli VM, Incani M, Cossu E, Congiu T, Scano F, Pilia S, Sentinelli F, Tiberti C, Cavallo MG, Loche S, Baroni MG (2010) Prevalence of type 1 diabetes autoantibodies (GADA, IA2, and IAA) in overweight and obese children. Diabetes Care 33:820-822

16. Marzullo P, Minocci A, Tagliaferri MA, Guzzaloni G, Di Blasio A, De Medici C, Aimaretti G, Liuzzi A (2010) Investigations of thyroid hormones and antibodies in obesity: leptin levels are associated with thyroid autoimmunity independent of bioanthropometric, hormonal, and weight-related determinants. J Clin Endocrinol Metab 95:39653972

17. Badaru A, Pihoker C (2012) Type 2 diabetes in childhood: clinical characteristics and role of $\beta$-cell autoimmunity. Curr Diab Rep 12: $75-81$

18. Winer DA, Winer S, Shen L, Wadia PP, Yantha J, Paltser G, Tsui H, Wu P, Davidson MG, Alonso MN, Leong HX, Glassford A, Caimol M, Kenkel JA, Tedder TF, McLaughlin T, Miklos DB, Dosch HM, Engleman EG (2011) B cells promote insulin resistance through modulation of $\mathrm{T}$ cells and production of pathogenic IgG antibodies. Nat Med 217:610-617

19. Miyazaki T, Hirokami Y, Matsuhashi N, Takatsuka H, Naito M (1999) Increased susceptibility of thymocytes to apoptosis in mice lacking AIM, a novel murine macrophage-derived soluble factor belonging to the scavenger receptor cysteine-rich domain superfamily. J Exp Med 189:413-422

20. Resnick D, Pearson A, Krieger M (1994) The SRCR superfamily: a family reminiscent of the Ig superfamily. Trends Biochem Sci 19:5-8

21. Mori M, Kimura H, Iwamura Y, Arai S, Miyazaki T (2012) Modification of $N$-glycosylation modulates the secretion and lipolytic function of apoptosis inhibitor of macrophage (AIM). FEBS Lett 586:3569-3574

22. Joseph SB, Bradley MN, Castrillo A, Bruhn KW, Mak PA, Pei L, Hogenesch J, O'Connell RM, Cheng G, Saez E, Miller JF, Tontonoz P (2004) LXR-dependent gene expression is important for macrophage survival and the innate immune response. Cell 119:299-309

23. Valledor AF, Hsu LC, Ogawa S, Sawka-Verhelle D, Karin M, Glass CK (2004) Activation of liver X receptors and retinoid X receptors prevents bacterial-induced macrophage apoptosis. Proc Natl Acad Sci U S A 101:17813-17818

24. Arai S, Shelton JM, Chen M, Bradley MN, Castrillo A, Bookout AL, Mak PA, Edwards PA, Mangelsdorf DJ, Tontonoz P, Miyazaki T (2005) A role of the apoptosis inhibitory factoAIM/Sp $\alpha /$ Api6 in atherosclerosis development. Cell Metab 1:201-213

25. Miyazaki T, Kurokawa J, Arai S (2011) AIMing at metabolic syndrome. -Towards the development of novel therapies for metabolic diseases via apoptosis inhibitor of macrophage (AIM).-. Circ J 75:2522-2531 
26. Gebe JA, Kiener PA, Ring HZ, Li X, Francke U, Aruffo A (1997) Molecular cloning, mapping to human chromosome $1 \mathrm{q} 21-\mathrm{q} 23$, and cell binding characteristics of Spalpha, a new member of the scavenger receptor cysteine-rich (SRCR) family of proteins. J Biol Chem 272:6151-6158

27. Gebe JA, Llewellyn M, Hoggatt H, Aruffo A (2000) Molecular cloning, genomic organization and cell-binding characteristics of mouse Spalpha. Immunology 99:78-86

28. Gangadharan B, Antrobus R, Dwek RA, Zitzmann N (2007) Novel serum biomarker candidates for liver fibrosis in hepatitis $\mathrm{C}$ patients. Clin Chem 53:1792-1799

29. Kim WK, Hwang HR, do Kim H, Lee PY, In YJ, Ryu HY, Park SG, Bae KH, Lee SC (2009) Glycoproteomic analysis of plasma from patients with atopic dermatitis: $\mathrm{CD} 5 \mathrm{~L}$ and $\mathrm{ApoE}$ as potential biomarkers. Exp Mol Med 40:677-685

30. Gray J, Chattopadhyay D, Beale GS, Patman GL, Miele L, King BP, Stewart S, Hudson M, Day CP, Manas DM, Reeves HL (2009) A proteomic strategy to identify novel serum biomarkers for liver cirrhosis and hepatocellular cancer in individuals with fatty liver disease. BMC Cancer 9:271

31. Kurokawa J, Arai S, Nakashima K, Nagano H, Nishijima A, Miyata K, Ose R, Mori M, Kubota N, Kadowaki T, Oike Y, Koga H, Febbraio M, Iwanaga T, Miyazaki T (2010) AIM is endocytosed into adipocytes and decreases lipid droplets via inhibition of fatty acid synthase activity. Cell Metab 11:479-492

32. Arai S, Maehara N, Iwamura $\mathrm{Y}$, Honda $\mathrm{S}$, Nakashima $\mathrm{K}$, Kai $\mathrm{T}$, Ogishi M, Morita K, Kurokawa J, Mori M, Motoi Y, Miyake K, Matsuhashi N, Yamamura K, Ohara O, Shibuya A, Wakeland EK, Li QZ, Miyazaki T (2013) Obesity-associated autoantibody production requires AIM to retain IgM immune complex on follicular dendritic cells. Cell Rep 3:1187-1198

33. Yusa S, Ohnishi S, Onodera T, Miyazaki T (1999) AIM, a murine apoptosis inhibitory factor, induces strong and sustained growth inhibition of B lymphocytes in combination with TGF- $\beta 1$. Eur $\mathrm{J}$ Immunol 29:1086-1093

34. Kuwata K, Watanabe H, Jiang SY, Yamamoto T, Tomiyama-Miyaji C, Abo T, Miyazaki T, Naito M (2003) AIM inhibits apoptosis of T cells and NKT cells in Corynebacterium -induced granuloma formation in mice. Am J Pathol 162:837-847

35. Qu P, Du H, Li Y, Yan C (2009) Myeloid-specific expression of Api6/ $\mathrm{AIM} / \mathrm{Sp}$ alpha induces systemic inflammation and adenocarcinoma in the lung. J Immunol 182:1648-1659

36. Vera J, Fenutría R, Cañadas O, Figueras M, Mota R, Sarrias MR, Williams DL, Casals C, Yelamos J, Lozano F (2009) The CD5 ectodomain interacts with conserved fungal cell wall components and protects from zymosan-induced septic shock-like syndrome. Proc Natl Acad Sci U S A 106:1506-1511

37. Akila P, Prashant V, Suma MN, Prashant SN, Chaitra TR (2012) CD163 and its expanding functional repertoire. Clin Chim Acta 413: 669-674

38. Ligtenberg AJ, Veerman EC, Nieuw Amerongen AV, Mollenhauer J (2007) Salivary agglutinin/glycoprotein-340/ DMBT1: a single molecule with variable composition and with different functions in infection, inflammation and cancer. Biol Chem 388:1275-1289

39. Martínez VG, Moestrup SK, Holmskov U, Mollenhauer J, Lozano F (2011) The conserved scavenger receptor cysteine-rich superfamily in therapy and diagnosis. Pharmacol Rev 63:967-1000

40. Zechner R, Strauss JG, Haemmerle G, Lass A, Zimmermann R (2005) Lipolysis: pathway under construction. Curr Opin Lipidol $16: 333-340$

41. Duncan RE, Ahmadian M, Jaworski K, Sarkadi-Nagy E, Sul HS (2007) Regulation of lipolysis in adipocytes. Annu Rev Nutr 27:79-101

42. Olsnes S, Klingenberg O, Wiedłocha A (2003) Transport of exogenous growth factors and cytokines to the cytosol and to the nucleus. Physiol Rev 83:163-182
43. Wesche J, Małecki J, Wiedłocha A, Skjerpen CS, Claus P, Olsnes S (2006) FGF-1 and FGF-2 require the cytosolic chaperone Hsp90 for translocation into the cytosol and the cell nucleus. J Biol Chem 281: 11405-11412

44. Lin SY, Makino K, Xia W, Matin A, Wen Y, Kwong KY, Bourguignon L, Hung MC (2001) Nuclear localization of EGF receptor and its potential new role as a transcription factor. Nat Cell Biol 3:802-808

45. Sandvig K, van Deurs B (2000) Entry of ricin and Shiga toxin into cells: molecular mechanisms and medical perspectives. EMBO J 19: 5943-5950

46. Sandvig K, van Deurs B (2005) Delivery into cells: lessons learned from plant and bacterial toxins. Gene Ther 12:865-872

47. Ackerman AL, Kyritsis C, Tampé R, Cresswell P (2005) Access of soluble antigens to the endoplasmic reticulum can explain crosspresentation by dendritic cells. Nat Immunol 6:107-113

48. Giodini A, Cresswell P (2008) Hsp90-mediated cytosolic refolding of exogenous proteins internalized by dendritic cells. EMBO J 27: 201-211

49. Wu Z, Rosen ED, Brun R, Hauser S, Adelmant G, Troy AE, McKeon C, Darlington GJ, Spiegelman BM (1999) Cross-regulation of C/EBP alpha and PPAR gamma controls the transcriptional pathway of adipogenesis and insulin sensitivity. Mol Cell 3:151-158

50. He W, Barak Y, Hevener A, Olson P, Liao D, Le J, Nelson M, Ong E, Olefsky JM, Evans RM (2003) Adipose-specific peroxisome proliferator-activated receptor gamma knockout causes insulin resistance in fat and liver but not in muscle. Proc Natl Acad Sci U S A 100:15712-15717

51. Holm C (2003) Molecular mechanisms regulating hormone-sensitive lipase and lipolysis. Biochem Soc Trans 31:1120-1124

52. Finn PF, Dice JF (2006) Proteolytic and lipolytic responses to starvation. Nutrition 22:830-844

53. Zechner R, Kienesberger PC, Haemmerle G, Zimmermann R, Lass A (2009) Adipose triglyceride lipase and the lipolytic catabolism of cellular fat stores. J Lipid Res 50:3-21

54. Girousse A, Langin D (2012) Adipocyte lipases and lipid dropletassociated proteins: insight from transgenic mouse models. Int J Obes (Lond) 36:581-594

55. Lafontan $\mathrm{M}$ (2008) Advances in adipose tissue metabolism. Int $\mathbf{J}$ Obes 32(Suppl 7):S39-S51

56. Iwamura Y, Mori M, Nakashima K, Mikami T, Murayama K, Arai S, Miyazaki T (2012) Apoptosis inhibitor of macrophage (AIM) diminishes lipid droplet-coating proteins leading to lipolysis in adipocytes. Biochem Biophys Res Commun 422:476-481

57. Matsusue K (2010) A physiological role for fat specific protein $27 /$ cell death-inducing DFF45-like effector $\mathrm{C}$ in adipose and liver. Biol Pharm Bull 33:346-350

58. Tontonoz P, Spiegelman BM (2008) Fat and beyond: the diverse biology of PPARgamma. Annu Rev Biochem 77:289-312

59. Tzameli I, Fang H, Ollero M, Shi H, Hamm JK, Kievit P, Hollenberg AN, Flier JS (2000) Regulated production of a peroxisome proliferatoractivated receptor-gamma ligand during an early phase of adipocyte differentiation in 3T3-L1 adipocytes. J Biol Chem 279:36093-36102

60. Forman BM, Chen J, Evans RM (1997) Hypolipidemic drugs, polyunsaturated fatty acids, and eicosanoids are ligands for peroxisome proliferator-activated receptors alpha and delta. Proc Natl Acad Sci U S A 94:4312-4317

61. Matsusue K, Kusakabe T, Noguchi T, Takiguchi S, Suzuki T, Yamano S, Gonzalez FJ (2008) Hepatic steatosis in leptin-deficient mice is promoted by the PPARgamma target gene Fsp27. Cell Metab 7:302-311

62. Dalen KT, Schoonjans K, Ulven SM, Weedon-Fekjaer MS, Bentzen TG, Koutnikova H, Auwerx J, Nebb HI (2007) Adipose tissue expression of the lipid droplet-associating proteins S3-12 and perilipin is controlled by peroxisome proliferator-activated receptorgamma. Diabetes 53:1243-1252 
63. Kurokawa J, Nagano H, Ohara O, Kubota N, Kadowaki T, Arai S, Miyazaki T (2011) Apoptosis inhibitor of macrophage (AIM) is required for obesity-associated recruitment of inflammatory macrophages into adipose tissue. Proc Natl Acad Sci U S A 108:12072-12077

64. Shi H, Kokoeva MV, Inouye K, Tzameli I, Yin H, Flier JS (2006) TLR4 links innate immunity and fatty acid-induced insulin resistance. J Clin Invest 116:3015-3025

65. Suganami T, Tanimoto-Koyama K, Nishida J, Itoh M, Yuan X, Mizuarai S, Kotani H, Yamaoka S, Miyake K, Aoe S, Kamei Y, Ogawa Y (2007) Role of the Toll-like receptor 4/NF-B pathway in saturated fatty acid-induced inflammatory changes in the interaction between adipocytes and macrophages. Arterioscler Thromb Vasc Biol 27:84-91

66. Poggi M, Bastelica D, Gual P, Iglesias MA, Gremeaux T, Knauf C, Peiretti F, Verdier M, Juhan-Vague I, Tanti JF, Burcelin R, Alessi MC (2007) $\mathrm{C} 3 \mathrm{H} / \mathrm{HeJ}$ mice carrying a toll-like receptor 4 mutation are protected against the development of insulin resistance in white adipose tissue in response to a high-fat diet. Diabetologia 50:1267-1276

67. Tsukumo DM, Carvalho-Filho MA, Carvalheira JB, Prada PO, Hirabara SM, Schenka AA, Araújo EP, Vassallo J, Curi R, Velloso LA, Saad MJ (2007) Loss-of-function mutation in Toll-like receptor 4 prevents diet-induced obesity and insulin resistance. Diabetes 56 : 1986-1998

68. Davis JE, Gabler NK, Walker-Daniels J, Spurlock ME (2008) Tlr-4 deficiency selectively protects against obesity induced by diets high in saturated fat. Obesity 16:1248-1255

69. Kamei N, Tobe K, Suzuki R, Ohsugi M, Watanabe T, Kubota N, Ohtsuka-Kowatari N, Kumagai K, Sakamoto K, Kobayashi M, Yamauchi T, Ueki K, Oishi Y, Nishimura S, Manabe I, Hashimoto H, Ohnishi Y, Ogata H, Tokuyama K, Tsunoda M, Ide T, Murakami K, Nagai R, Kadowaki T (2006) Overexpression of monocyte chemoattractant protein-1 in adipose tissues causes macrophage recruitment and insulin resistance. J Biol Chem 281:26602-26614

70. Kanda H, Tateya S, Tamori Y, Kotani K, Hiasa K, Kitazawa R, Kitazawa S, Miyachi H, Maeda S, Egashira K, Kasuga M (2006) MCP-1 contributes to macrophage infiltration into adipose tissue, insulin resistance, and hepatic steatosis in obesity. J Clin Invest 116:1494-1505

71. Keophiphath M, Rouault C, Divoux A, Clément K, Lacasa D (2010) CCL5 promotes macrophage recruitment and survival in human adipose tissue. Arterioscler Thromb Vasc Biol 30:39-45

72. Soma MR, Mims MP, Chari MV, Rees D, Morrisett JD (1992) Triglyceride metabolism in 3T3-L1 cells. An in vivo ${ }^{13} \mathrm{C}$ NMR study. J Biol Chem 267:11168-11175

73. Kopp A, Gross P, Falk W, Bala M, Weigert J, Buechler C, Neumeier M, Schölmerich J, Schäffler A (2009) Fatty acids as metabolic mediators in innate immunity. Eur J Clin Invest 39:924-933

74. Schaeffler A, Gross P, Buettner R, Bollheimer C, Buechler C, Neumeier M, Kopp A, Schoelmerich J, Falk W (2009) Fatty acidinduced induction of Toll-like receptor-4/nuclear factor-kappaB pathway in adipocytes links nutritional signalling with innate immunity. Immunology 126:233-245

75. Miura T, Miki T (2009) GSK-3beta, a therapeutic target for cardiomyocyte protection. Circ J 73:1184-1192

76. Kantor AB, Herzenberg LA (1993) Origin of murine B cell lineages. Annu Rev Immunol 11:501-538

77. Hardy RR, Hayakawa K (1994) CD5 B cells, a fetal B cell lineage. Adv Immunol 55:297-339

78. Boes M (2000) Role of natural and immune IgM antibodies in immune responses. Mol Immunol 37:1141-1149
79. Pepys MB (1976) Role of complement in the induction of immunological responses. Transplant Rev 32:93-120

80. Ahearn JM, Fearon DT (1989) Structure and function of the complement receptors, CR1 (CD35) and CR2 (CD21). Adv Immunol 46: $183-219$

81. Heyman B (1990) The immune complex: possible ways of regulating the antibody response. Immunol Today 11:310-313

82. Carroll MC (1998) The role of complement and complement receptors in induction and regulation of immunity. Annu Rev Immunol 16: $545-568$

83. Allen CD, Cyster JG (2008) Follicular dendritic cell networks of primary follicles and germinal centers: phenotype and function. Semin Immunol 20:14-25

84. Tissot JD, Sanchez JC, Vuadens F, Scherl A, Schifferli JA, Hochstrasser DF, Schneider P, Duchosal MA (2002) IgM are associated to Sp alpha (CD5 antigen-like). Electrophoresis 23:1203-1206

85. Boes M, Esau C, Fischer MB, Schmidt T, Carroll M, Chen J (1998) Enhanced B-1 cell development, but impaired IgG antibody responses in mice deficient in secreted IgM. J Immunol 160:47764787

86. Shibuya A, Sakamoto N, Shimizu Y, Shibuya K, Osawa M, Hiroyama T, Eyre HJ, Sutherland GR, Endo Y, Fujita T, Miyabayashi T, Sakano S, Tsuji T, Nakayama E, Phillips JH, Lanier LL, Nakauchi H (2000) Fc alpha/mu receptor mediates endocytosis of IgM-coated microbes. Nat Immunol 1:441-446

87. Honda S, Kurita N, Miyamoto A, Cho Y, Usui K, Takeshita K, Takahashi S, Yasui T, Kikutani H, Kinoshita T, Fujita T, TaharaHanaoka S, Shibuya K, Shibuya A (2009) Enhanced humoral immune responses against T-independent antigens in $\mathrm{Fc}$ alpha/muRdeficient mice. Proc Natl Acad Sci U S A 106:11230-11235

88. MacLennan IC, Gray D, Kumararatne DS, Bazin H (1982) The lymphocytes of splenic marginal zones: a distinct B-cell lineage. Immunol Today 3:305-307

89. Lopes-Carvalho T, Kearney JF (2004) Development and selection of marginal zone B cells. Immunol Rev 197:192-205

90. Pillai S, Cariappa A, Moran ST (2005) Marginal zone B cells. Annu Rev Immunol 23:161-196

91. Oliver AM, Martin F, Kearney JF (1999) IgMhighCD21high lymphocytes enriched in the splenic marginal zone generate effector cells more rapidly than the bulk of follicular B cells. J Immunol 162:71987207

92. Meyer-Bahlburg A, Bandaranayake AD, Andrews SF, Rawlings DJ (2009) Reduced c-myc expression levels limit follicular mature B cell cycling in response to TLR signals. J Immunol 182:4065-4075

93. Li QZ, Xie C, Wu T, Mackay M, Aranow C, Putterman C, Mohan C (2005) Identification of autoantibody clusters that best predict lupus disease activity using glomerular proteome arrays. J Clin Invest 115: 3428-3439

94. Li QZ, Zhou J, Wandstrat AE, Carr-Johnson F, Branch V, Karp DR, Mohan C, Wakeland EK, Olsen NJ (2007) Protein array autoantibody profiles for insights into systemic lupus erythematosus and incomplete lupus syndromes. Clin Exp Immunol 147:60-70

95. Li QZ, Zhou J, Lian Y, Zhang B, Branch VK, Carr-Johnson F, Karp DR, Mohan C, Wakeland EK, Olsen NJ (2010) Interferon signature gene expression is correlated with autoantibody profiles in patients with incomplete lupus syndromes. Clin Exp Immunol 159:281291

96. Underhill GH, Minges Wols HA, Fornek JL, Witte PL, Kansas GS (2002) IgG plasma cells display a unique spectrum of leukocyte adhesion and homing molecules. Blood 99:2905-2912 